\title{
Proposta de automação da produção de massa de queijo com controle de nível e de temperatura
}

Este trabalho apresenta uma proposta de automação e controle do processo fabricação de massa de queijos tipo minas frescal, utilizando um sistema de controle de nível e de temperatura para o leite. O protótipo é composto por três reservatórios, sendo um utilizado para o leite crú, outro para o coagulante e o último para realizar a mistura (leite + coagulante). Utilizaram-se também de duas bombas centrífugas, sensores de nível e temperatura, aquecedor de resistência elétrica, agitador mecânico e placa de controle microcontrolada. A ação de controle on-off foi utilizada para o monitoramento do de nível de líquido nos tanques, aquecedor de resistência elétrica, agitador e a temperatura (LM35) do leite. Através do algoritmo desenvolvido no software do compilador TBASIC, o tempo de coagulação do leite foi pré-definido e controlado. O protótipo demonstrou bons resultados, funcionando com eficácia e respondendo de forma positiva os resultados esperados, tornando-se uma alternativa viável para automação do processo de fabricação de massa de queijo.

Palavras-chave: Automação; Sensores; On/Off; Indústria de laticínio; Fabricação de queijo.

\section{Roposal to automate the production of cheese pasta with level and temperature control}

This work presents a proposal for automation and control of the pasta production process of fresh Minas cheese, using a level and temperature control system for milk. The prototype consists of three reservoirs, one used for raw milk, another for coagulant and the last one for mixing (milk + coagulant). Two centrifugal pumps, level and temperature sensors, electric resistance heater, mechanical stirrer and microcontrolled control board were also used. The on-off control action was used to monitor the liquid level in the tanks, electric resistance heater, stirrer and the milk temperature (LM35). Through the algorithm developed in the TBASIC compiler software, the milk's clotting time was pre-defined and controlled. The prototype demonstrated good results, working effectively and responding positively to the expected results, making it a viable alternative for automating the cheese dough manufacturing process.

Keywords: Automation; Sensor; On/Off; Dairy industry; Cheese making.

Topic: Inovação Tecnológica

Reviewed anonymously in the process of blind peer.
Received: 06/03/2021

Approved: 23/03/2021
Ananza Di Renzo dos Santos (iD)

Universidade do Estado de Mato Grosso, Brasil

http://lattes.cnpq.br/0076698727298287

http://orcid.org/0000-0001-8031-4445

nanza_linkis12@hotmail.com

Ivana Bevilacqua de Menezes (iD

Universidade do Estado de Mato Grosso, Brasil

http://lattes.cnpq.br/8406082129799993

http://orcid.org/0000-0002-5991-4806

ivana_spz@hotmail.com

Tadeu Miranda de Queiroz

Universidade do Estado de Mato Grosso, Brasil

http://lattes.cnpq.br/2582121765769124

http://orcid.org/0000-0002-1959-7658

tdmqueiroz@unemat.br
Referencing this:

SANTOS, A. R.; MENEZES, I. B.; QUEIROZ, T. M.. Proposta de automação da produção de massa de queijo com controle de nível e de temperatura. Revista Ibero Americana de Ciências Ambientais, v.12, n.3, p.458-468, 2021. DOI: http://doi.org/10.6008/CBPC2179$\underline{6858.2021 .003 .0037}$ 


\section{INTRODUÇÃO}

A indústria de laticínio chegou ao Brasil no início do ano de 1950 para produção de leite pasteurizado e no final do ano de 1960 para produção de queijo, pois foi nesses anos que se deu a chegada dos equipamentos para que ocorresse a automação (LIMA et al., 2017).

A automação consiste num conjunto de técnicas cuja finalidade é construir um sistema operacional que trabalha com eficiência das informações recebidas o qual opera, agregando a vantagem de ser capaz de melhorar de forma considerável qualquer controle de processo de produção com menor custo, maior qualidade e menor tempo. Nas indústrias é ideal que a ação de controle seja On/Off pois é de simples controle e consiste num circuito que analisa e compara os sinais de entrada e saída (BOUFLEUR et al., 2014), embora existam outras ações de controle mais refinadas, porém, exigem maior conhecimento técnico para implantação e operação, além de maior dispêndio de recursos.

Devido aos avanços tecnológicos, muitas operações de processo nas indústrias mudaram radicalmente, pois a tecnologia computacional tornou-se a ferramenta para a revolução nas empresas que buscam o crescimento e aumento de eficiência dos processos e qualidade dos produtos. A automação dos processos de leite e derivados em propriedades leiteiras é uma realidade somente para grandes empresas e quanto às microempresas e pequenos produtores já é considerada uma visão surreal, devido principalmente à indisponibilidade financeira para investimentos, pois é um risco para a rentabilidade e sustentabilidade no processo (BOTEGA et al., 2008).

Apesar de toda aplicação da automação um laticínio ainda contém muitas operações heterogêneas, isto é, há um conjunto moderno de equipamentos em diferentes estágios ou células tecnológicas e um conjunto de unidades que são artesanais, tais como a fabricação do queijo e manteiga. Embora haja possiblidade de fazer a automação o custo prévio de um equipamento automático que abrange essas unidades artesanais é muito elevado e muitas vezes a capacidade do equipamento é alta para início de uma produção de pequeno porte, sendo desvantajosa a compra, como exemplo, cita-se a QUEIJOMATIC com capacidade de até 10 mil litros de leite por hora.

Além disso, Sangaletti et al. (2009) destacam que a fabricação artesanal de queijos tipo minas frescal não é padronizada, resultando em um produto de constituição variável, especialmente em relação à proteína e gorduras. Os autores citam ainda que, durante o processo de fabricação podem ocorrer perigos que irão comprometer a qualidade do produto final, sendo um deles a temperatura inadequada de fabricação.

Neste sentido, Oliveira et al. (2017a) avaliando queijos minas frescal e mussarela verificaram que $55,6 \%$ dos queijos minas frescal não atendiam aos padrões da legislação para coliformes totais. Os autores enfatizaram a necessidade de adoção de boas práticas de fabricação para redução da contaminação. Isso posto, verifica-se que a automação do processo pode ser uma ferramenta capaz de diminuir a manipulação da matéria prima e oportunizar um processo de fabricação mais higiênico.

Olson (1970) publicou um dos primeiros trabalhos mundiais sobre automação da fabricação de queijos, onde destaca como vantagens da mecanização do processo fabril a padronização da produção, a 
redução da contaminação microbiológica e a redução dos custos, sendo que o último foi o fator que deu o maior impulso à mecanização. Desde então a busca por processos fabris automáticos são realidade em todo o mundo, principalmente nos processos de fabricação de alimentos pelo fato da redução ou eliminação da manipulação de matéria prima, o que reduz consideravelmente a contaminação.

Pivaro (2016) traz uma ampla descrição de processos e equipamentos destinados à automação de processos fabris da indústria de laticínios, onde se observa diversidade de opções em relação a marcas, capacidade de processamento, nível de automação e custo, inclusive para o processo de fabricação de massa de queijos e até de processo completo de fabricação de queijos, onde de um lado da planta fabril entra o leite pasteurizado e demais insumos e do outro lado sai queijos prontos e embalados.

Portanto, o presente estudo não tem a pretensão de apresentar um processo novo, mas tem o objetivo de desenvolver o protótipo de uma 'queijadora' automatizada para produção de massa de queijos, com o intuito de facilitar o processo fabril dos pequenos empresários e microempresários, e até da agroindústria familiar, os quais não têm condições de abarcar capacidade de investimento para compra de um equipamento sofisticado e de alto custo. Com isso, propõem-se a redução de operações artesanais e consequentemente o alcance de maior qualidade sensorial do produto, bem como, maior confiabilidade sanitária e padronização da produção.

\section{MATERIAIS E MÉTODOS}

O protótipo com sistema automático para produção de massa de queijo foi desenvolvido com a finalidade de aplicar e aprimorar técnicas de controle de processos desenvolvidas no Laboratório de Automação e Controle (LAC), do Campus Universitário Deputado Estadual Renê Barbour, na cidade de Barra do Bugres - MT, pertencente à Universidade do Estado do Mato Grosso.

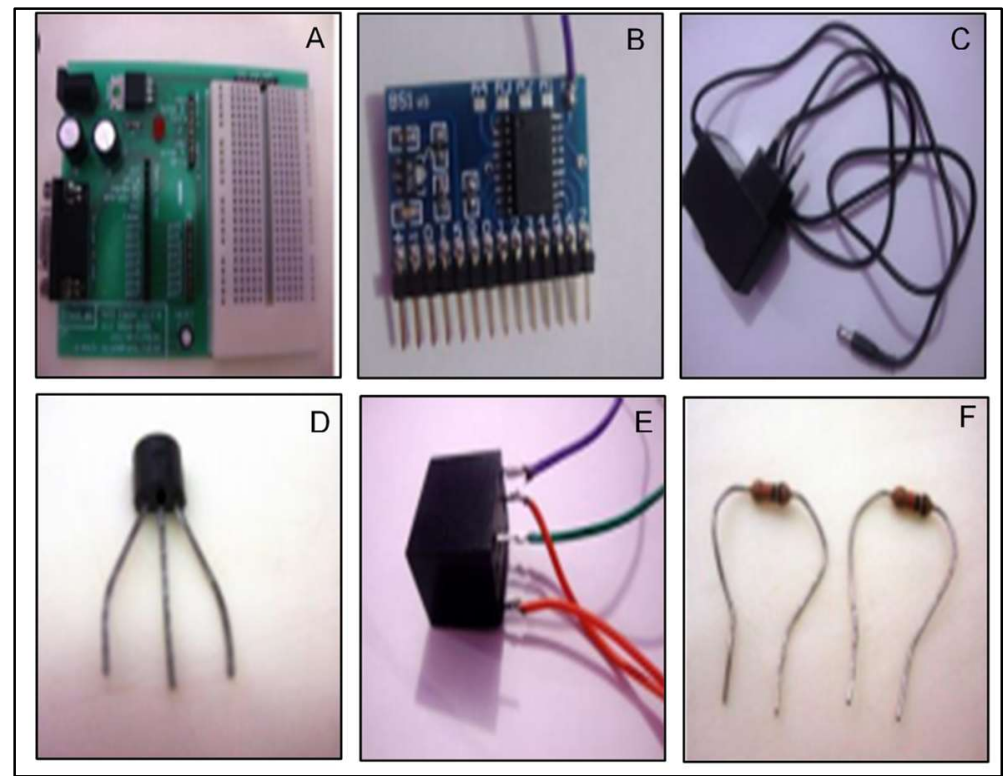

Figura 1: Materiais utilizados: Placa Step Lab (A), Microcontrolador Basic Step 1 (B), Fonte de Alimentação (C), Transistor NPN (D), Rele 5 pinos (E) e Resistores $1 / 4 \mathrm{~W}(\mathrm{~F})$.

Os equipamentos empregados para a construção do projeto serão expostos no decorrer do trabalho, 
dando ênfase às particularidades operacionais de cada elemento e sua aplicação no protótipo, juntamente com as etapas descritas de montagem do circuito. Na Figura 1, apresentam-se alguns dos materiais eletrônicos utilizados na construção do protótipo.

A placa StepLab (Figura 1.A), serve para conexão do microcontrolador Basic Step, o Display de Cristal Líquido (LCD) e outros componentes eletrônicos integrados (FIGUEREDO et al., 2006; VILELA et al., 2001), através de uma matriz de contatos e outros pinos que permitem a realização de testes e simulações. Essa placa também é o elo de comunicação com um computador, onde é digitado o algoritmo de controle, sendo o mesmo transmitido ao microntrolador por meio de um cabo serial (RS-232), evitando a necessidade de preparações especiais para comunicação do Basic Step com o Computador, uma vez que tais preparações de comunicação já estão inseridas na Step Lab e no Basic Step.

Os microcontroladores, a exemplo do Basic Step (Figura 1.B), são definidos como um sistema computacional integrado, ou seja, possuem uma unidade de processamento, memória, entradas e saídas de dados em apenas um chip. Atualmente o Basic Step ganha maior destaque entre os microcontroladores, pois apresenta baixo custo e praticidade na sua operação (REBELLO JUNIOR, 2004).

Na Figura 1.C destaca-se a fonte de alimentação do microcontrolador através da Placa Step Lab, a qual possui entrada AC variando de 110 a 220 VCA e saída, retificada por ponte de diodos, de 12 VCC. Desse modo a alimentação do microcontrolador dispensa a utilização de pilhas, baterias ou qualquer outro aparato eletrônico, o que facilita a sua utilização (RIZZOLO, 2010).

O transistor (Figura 1.D) é um dispositivo semicondutor de silício com três terminais, sendo eles: a base, o emissor e o coletor, os quais controlam a passagem de correntes entre o coletor e emissor a partir do controle da corrente aplicada na base. Tem como finalidade principal à amplificação e o chaveamento em circuitos elétricos, onde na amplificação, o sinal de saída é igual ao de entrada, mas com maior amplitude, devido à potência fornecida pela fonte de alimentação, logo controla o fluxo de corrente elétrica e proporciona o chaveamento comportando-se como chave liga-desliga eletrônica (VALERO et al., 2014).

Relés (Figura 1.E) são definidos como dispositivos fundamentais de manobra de cargas elétricas, pois proporcionam uma combinação lógica de comando e a separação dos circuitos de potência e comando. Os relés constituídos de uma carcaça com cinco terminais são considerados os mais práticos, onde os terminais 1 e 2 se referem à bobina de excitação, o 3 é a entrada e o 4 e 5 pertencem aos contatos normalmente fechado (NF) e normalmente aberto (NA), respectivamente (SILVA, 2015).

A finalidade do resistor (Figura 1.F) é oferecer uma resistência elétrica à passagem da corrente, quanto maior for a corrente direcionada a um resistor, maior será a quantidade de calor gerada por ele, que precisará ser transferida ao ambiente. Existe um sistema padrão que é adotado para identificar a resistência analisada, onde os resistores possuem de três a cinco faixas de cores, se tornando um código (BRAGA, 2005). Para o trabalho foram utilizados cinco resistores com potência de $1 / 4 \mathrm{~W}$, sendo que quatro deles são de $10 \mathrm{k} \Omega$ e um de $3,3 \mathrm{k} \Omega$.

Além dos componentes ilustrados na Figura 1, utilizou-se também de um LCD de duas linhas com 20 posições em cada uma delas, permitindo a escrita de caracteres alfanuméricos e alguns símbolos. Isso facilita 
a visualização do andamento do algoritmo processado pelo microcontrolador, permitindo ao usuário ver a leitura de informações de forma direta, as quais se referem aos comandos e ações de controle. No Basic Step, o display usa a comunicação serial, sendo utilizado em conjunto, logo é necessário um pino de trafego de dados seriais para a comunicação. Através do comando serout, as informações que são processados no Basic Step são enviadas ao display (FIGUEREDO et al., 2006).

Na Figura 2 ilustra-se o mini contator, a minibomba centrífuga e o sensor de temperatura utilizado no protótipo.

A

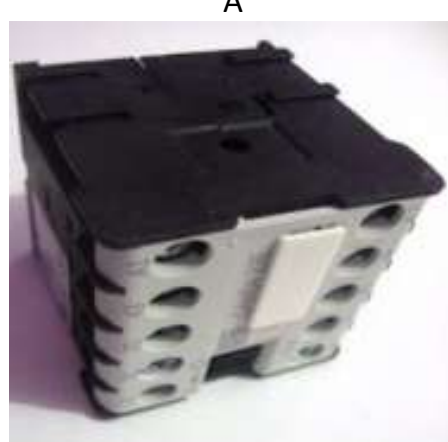

B

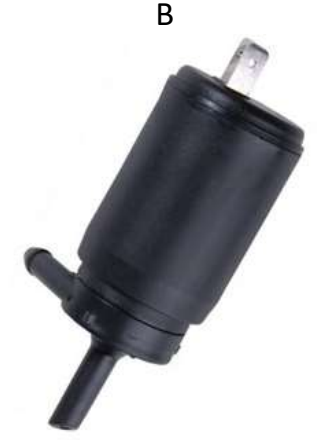

c

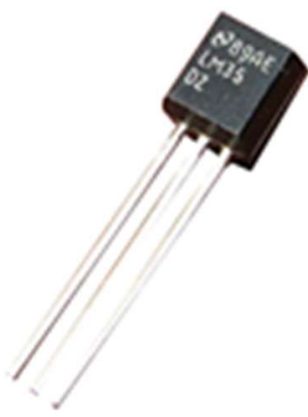

Figura 2: Componentes elétricos utilizados: Mini contator (A), minibomba centrífuga (B) e Sensor de Temperatura (C).

Segundo Silva (2015), o contator (Figura 2.A) é descrito como uma chave de comutação eletromagnética direcionada em grande maioria para cargas de maior potência. Os contatos principais e os auxiliares Normalmente Aberto (NA) e Normalmente Fechado (NF) com capacidade menor de corrente, são utilizados para a energização de carga, auxiliando os circuitos de comando e sinalização, como também o acionamento de outros aparelhos elétricos de menor potência. Neste projeto utilizou-se de um mini contator auxiliar, uma vez que as cargas elétricas envolvidas nas etapas do processo foram pequenas, todavia, a teoria utilizada se aplica a qualquer tamanho de contator, dispensando adaptações no circuito elétrico de comando.

As bombas centrifugas (Figura 2.B), originalmente utilizadas em sistema de injeção de água do sistema de limpa para-brisas veicular, foram utilizadas para transferir o leite e o coalho dos tanques de armazenamento para o tanque de mistura. Essas bombas são feitas de material plástico e apresentam motor elétrico que funciona com uma tensão de 8 ou 12 VCC, sendo consideradas miniaturas de bombas centrifugas industriais, além de ter uma vazão máxima em torno de $86 \mathrm{~mL} \mathrm{~s}^{-1}$, a qual se mostrou adequada para as necessidades do protótipo. Uma vez conhecida a vazão da bomba a aferição do volume bombeado foi controlado pelo tempo de bombeamento se apoiando na definição de vazão, qual seja: $Q=V / t$, sendo $Q$ a vazão em $\mathrm{mL} \mathrm{s}^{-1}, \mathrm{~V}$ o volume em $\mathrm{mL}$ e t o tempo em $\mathrm{s}$.

A escolha do sensor de temperatura LM35 (Figura 2.C), foi motivada por ser um dispositivo de fácil leitura, contendo uma interface simples, baixo custo, disponibilidade imediata e ser amplamente utilizado em vários projetos de automação (BARBOSA et al., 2018).

Para controlar o nível do reservatório onde acontece a mistura do leite e coalho foi construído um sensor de nível, o qual possui uma ampola de mercúrio fixada na parte superior de uma pequena boia que quando movimentada gera a leitura de nível, à semelhança do que fizeram Almeida Junior et al. (2016). No 
tanque de armazenamento de leite foi utilizado um sensor de nível comercial que funciona pelo efeito Hall, o qual estava disponível no momento.

Na Figura 3 apresenta-se o diagrama esquemático dos componentes principais do protótipo, ilustrando o tanque de armazenamento do leite, o reservatório de coalho, o tanque de mistura e coagulação, as bombas injetoras, o agitador, o aquecedor resistivo, o sensor de temperatura e os sensores de nível (L do tanque de Leite e $\mathrm{M}$ do tanque de Mistura).

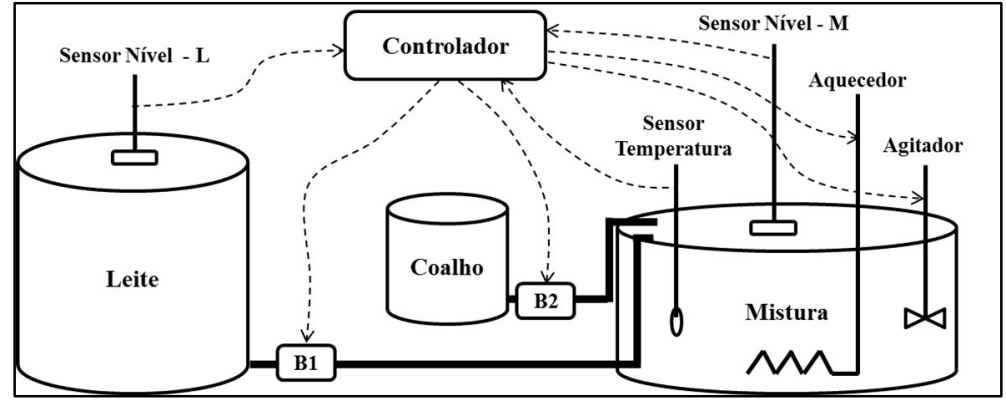

Figura 3: Ilustração dos componentes principais do protótipo e suas interligações com o controlador.

A conversão do sinal de resposta do sensor LM 35 para temperatura foi feita utilizando-se da função de resposta disponibilizada pelo fabricante (TEXAS INSTRUMENT, 2017). O conversor analógico-digital do microcontrolador Basic Step possui resolução binária de 10 bits, o que lhe permite 1024 combinações binárias (0 e 1), sendo o zero uma delas, portanto o valor máximo da variável resposta é $1023\left(2^{10}-1\right)$. Valendo-se dessa informação e da função de resposta do sensor, foi possível ajustar uma equação para converter o sinal do sensor de mili volts para temperatura em graus Celsius. Procedimento semelhante foi adotado por Silva et al. (2014) em um protótipo de sensor de luz wireless.

Nessa proposta considerou-se o leite pasteurizado previamente, ocupando-se apenas com a automação e controle do processo de coagulação do leite para obter a massa de queijo. Uma alternativa de automação e controle do processo de pasteurização do leite pode ser visto com detalhes em Barbosa et al. (2018).

\section{RESULTADOS}

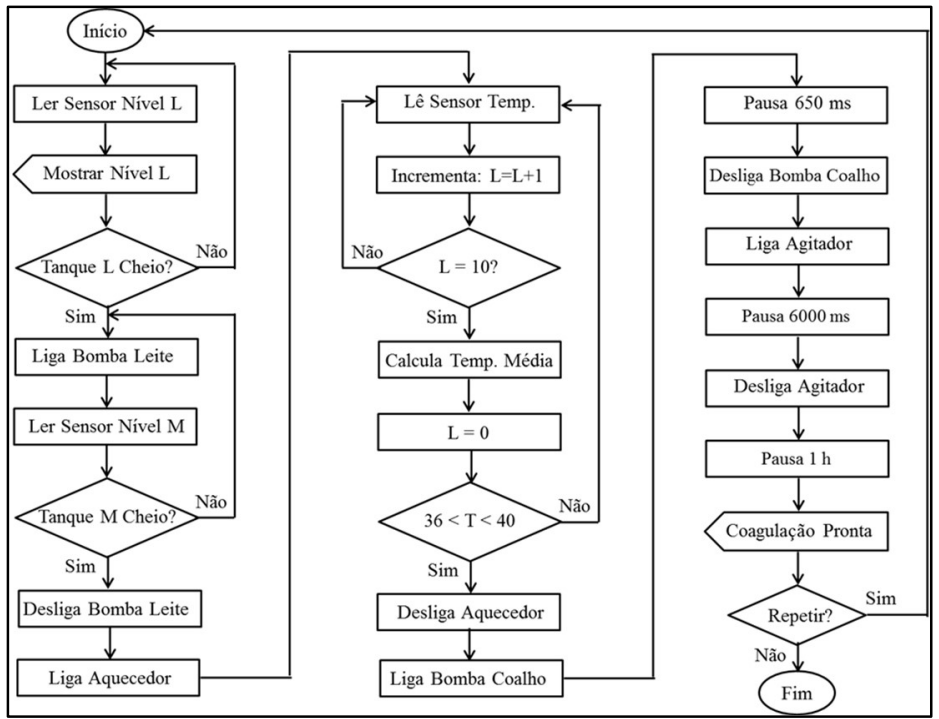

Figura 4: Fluxograma do processo de controle das etapas de fabricação de massa de queijo. 
A sequência dos comandos executados pelo algoritmo no processo está demonstrada através do fluxograma apresentado na Figura 4, por onde pode se observar as leituras dos sensores de nível e temperatura, bem como a sequência de acionamentos das bombas, agitador e aquecedor. O sistema funcionou em batelada executando a sequência de acionamentos até completar um ciclo de produção, os quais são delimitados por instruções de início e fim. Observam-se também as estruturas de repetição e tomada de decisão de máquina.

Na Figura 5 apresenta-se o diagrama esquemático do circuito eletro-eletrônico e de seus componentes desenvolvido para automação e controle do processo de fabricação de massa de quijo. A unidade central de controle é o microcontrolador Basic Step o qual está ligado aos demais periféricos de leitura de dados (sensores), dispositivos de acionamento (atuadores) e de interface homem máquina (LCD).

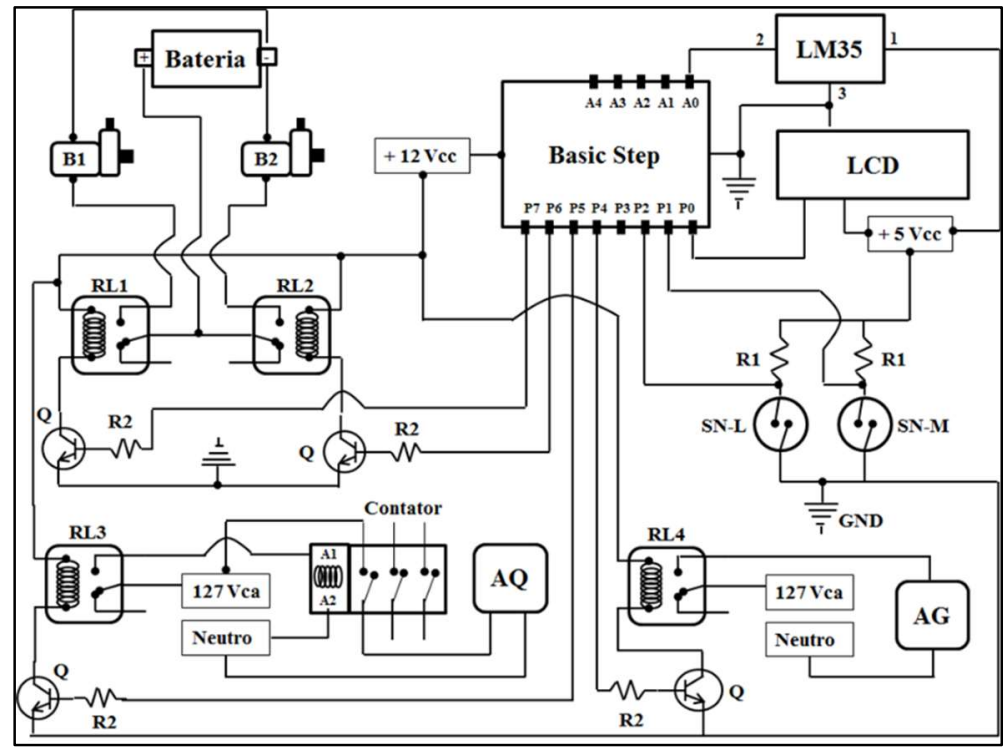

B1 e B2: Mini bombas centrífugas; Bateria: Bateria veicular de 12 Vcc, 60A; Basic Step: microcontrolador; LCD: Display de Cristal Líquido; LM-35: Sensor de Temperatura; RL: Rele 5 pinos 12 Vcc; Q: Transistor B548C; R1: Resistor 1/4 W de 3,3 k?; R2: Resistor 1/4 W de 3,3 k? ?; AQ: Aquecedor resistivo de 2000 W; AG: Agitador rotativo de pás; SN-L e SN-M: Sensores de nível dos tanques de Leite e Mistura, respectivamente; GND: Aterramento; Vcc: Volt Corrente Contínua; Vca: Volta Corrente Alternada; Contator: Mini contator auxiliar.

Figura 5: Diagrama esquemático do circuito eletro-eletrônico de automação e controle do protótipo.

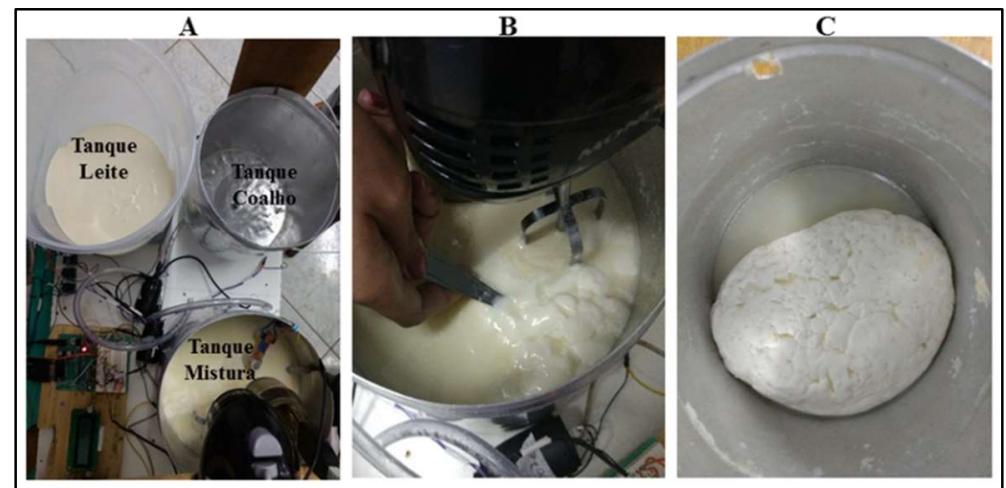

Figura 6: Vista superior do protótipo (A), tanque de mistura (B) e massa de queijo pronta (C).

Na Figura 6, apresentam-se as etapas de produção da massa de queijo executadas automaticamente, de onde se pode observar a fase inicial onde o leite e coagulante estavam em reservatórios separados, a fase intermediária onde o leite e o coagulante já estavam postos no tanque de mistura e a fase final, qual seja: a 
formação de coágulos e da massa de queijo.

\section{DISCUSSÃO}

O processo de produção a massa de queijo tipo minas frescal se iniciou com a verificação do nível do tanque de armazenamento de leite e na sequencia o algoritmo desenvolvido para controle do processo de produção de queijo, acionou a bomba 1 (Tanque de Leite) injetando leite no tanque misturador (M), até que o sensor de nível detectasse a leitura do nível máximo no tanque M. Em seguida, o aquecedor de resistência elétrica foi acionado juntamente com a leitura do sensor de temperatura, permanecendo ligado até que o leite no tanque $\mathrm{M}$ atingisse uma temperatura $38 \pm 2{ }^{\circ} \mathrm{C}$ (VIEIRA et al., 2004).

Ao atingir a temperatura determinada a bomba 2 do tanque de Coalho foi acionada para introduzir o coalho no tanque de mistura, e também o agitador foi acionado, o qual agitou a mistura por 6 segundos realizando a homogeneização do leite e coalho, e por fim foi desligado juntamente com a resistência elétrica de aquecimento. Na sequência, o display disponibilizou um contador, cuja finalidade foi fazer uma contagem até 3600 segundos (1 hora), para que ocorresse a formação dos coágulos no leite. Ao final de uma hora a formação da massa do queijo ficou pronta, como programado e esperado, indicando eficiência do sistema de controle.

O controle ON/OFF se mostrou adequado, uma vez que o sistema foi capaz de funcionar de forma continua e finalizou a ativadade programada apenas quando o último comando foi executado. Dados semelhantes foram obtidos por Boufleur et al. (2014), os quais usufruiram de um sistema automático com controle de temperatura e nível em um protótipo de produção de chá vegetal. E por fim, o microcontrolador atuou positivamente de forma independente e continua após a memorização do algoritimo, como foi perceptivel também nos estudos realizados por Rueda et al. (2006).

O sensor de LM 35 foi capaz de monitorar a temperatura com precisão o que permitiu o correto controle dessa variável dentro dos limites estabelecidos no algorítimo. Silva et al. (2014) quando trabalharam com o mesmo tipo de sensor de temperatura destacaram como vantagem a ótima linearidade de resposta para a faixa de temperatura desejada, qual seja: 0 a $150 \stackrel{\circ}{ } \mathrm{C}$. Tal resultado demonstra que a escolha desse sensor foi acertada e revela o seu pontencial para outras aplicações. No que diz respeito aos sensores de nível utilizados (um fabricado artesanalmente no LAC e outro comercial), os resultados para detecção de nível foram incontextáveis, pois os mesmos funcionaram adequadamente permitindo um eficiente controle do nível dos reservatórios. Almeida Junior et al. (2016) e Macedo et al. (2016) também constataram boa eficiência no funcionamento de sensores fabricados artesanalmente e comerciais, respectivamente, utilizados no controle de nível de protópicos automáticos dedicados a processos da industria de alimentos. Oliveira et al. (2017b) também implementaram um sistema de controle automático de nível e verificaram que a distância entre o sensor e o controlador não influenciou a leitura do sinal do sensor pelas portas lógicas. Os autores também concluíram que o sistema melhorou a eficiência dos reservatórios com economia de água e energia o que certamente converge para a economia de recurssos financeiros.

Quando o sistema foi posto em operação, constatou-se que o seu funcionamento ocorreu de forma 
perfeita, ordenada e coerente com a programação realizada e armazenada no microcontrolador Basic Step. O processo transcorreu de forma continua por uma hora até o seu desligamento após formação dos coágulos que dão origem à massa de queijo. Souto Neto et al. (2019) propuseram um sistema de controle para uma bancada de laboratório para ensino em controle de processos os quais atestaram o bom funcionamento do sistema e demonstraram a diversidade de aplicação dos sistemas de controle automáticos baseados em Controladores Lógicos Programáveis (CLP).

Especificamente sobre a fabricação automática de queijos, Cuaical (2017) desenvolveu um sistema de automação e controle do processo de fabricação de queijos maduros para a região do norte do Equador, donde observava como principais problemas da fabricação artesanal, a falta de padronização, o descontrole do tempo, a contaminação microbiológica e a falta de higiene. A partir da instrumentação do processo fabril em uma planta modelo, obteve sucesso em todas as etapas e chamou a atenção para o cuidado que se deve ter com a temperatura, especialmente na fase de pasteurização do leite e com a qualidade do coalho utilizado. Os problemas motivadores do trabalho do autor supracitado corroboram às observações de Olson (1970), e endossam a importância e aplicabilidade do presente trabalho.

Já no Brasil, Silva (2015), avaliando características microbiológicas de queijos minas frescal produzidos de forma artesanal em uma fazenda e queijos produzidos em uma indústria na região de Rio Verde, estado de Goiás, encontrou piores resultados para a presença de Salmonela no queijo artesanal, onde todas as amostras deram resultado positivo. Isso mostra a importância dos processos de automação, os quais reduzem a manipulação da matéria prima diminuindo as oportunidades de contaminação. Todavia, a automação do processo fabril não elimina totalmente a contaminação do produto final, fato que ficou evidente no trabalho de Silva (2015), uma vez que o queijo industrializado também apresentou contaminação, embora em menor frequência, o que pode ser devido à contaminação pré-existente na matéria prima, segundo o autor do trabalho.

Souza et al. (2017) avaliando a qualidade de queijos do tipo minas frescal produzidos por processos artesanais e industriais, os quais são comercializados na Zona da Mata Mineira, verificaram que os queijos artesanais apresentaram contaminação por coliformes acima do permitido pela legislação em $71 \%$ das amostras, já os queijos industrializados apresentaram contaminação apenas em 35\%. Esse resultado é mais uma evidência da importância da automação na indústria de alimentos com vistas à redução da manipulação da matéria prima e melhor controle sanitário do processo.

Isso posto, verifica-se que o protótipo automático para fabricação de massa de queijo, proposto neste trabalho, se assemelha a outras propostas existentes, porém com menor grau de sofisticação, uma vez que foi desenvolvido utilizando-se de materiais de baixo custo com a finalidade de demonstrar a teoria de controle e a real possibilidade de automação desse processo. Um protótipo aplicado à indústria deve contar com material adequado à legislação, como por exemplo, tanques, tubulações, bombas e acessórios fabricados em aço inoxidável. 


\section{CONCLUSÕES}

O protótipo do sistema automático de controle de nível e de temperatura para produção de massa de queijo mostrou-se eficiente durante a realização dos testes, funcionando conforme o esperado. 0 prototipo construido é de imensa importância para a aplicação de micro e pequenas empresas as quais poderam conseguir obter processos semelhantes a uma industria de grande porte de alimentos, pois abrange um processo de automação industrial, com o intuito de simplificar as fabricações artesanais de queijos, assim como, sua qualidade e segurança sanitária, operando automaticamente com ordenação e de forma continua com execução de varias etapas.

\section{REFERÊNCIAS}

ALMEIDA JUNIOR, E. S.; ROSÁRIO, G. O.; COSTA, A. K.; QUEIROZ, T. M.. Protótipo alternativo de desidratador osmótico com controle automático de nível e temperatura da solução de sacarose. Revista Engenharia e Tecnologia, v.8, n.2, p.152-160, 2016.

BARBOSA, C. M. D.; RODRIGUES, C. V.; PETTENON, D. A.; QUEIROZ, T. M.. Automação de um processo alternativo da pasteurização do leite utilizando ação de controle on-off. Revista Engenharia e Tecnologia, v.10, n.1, p.41-52, 2018.

BOTEGA, J. V. L.; BRAGA JÚNIOR, R. A.; LOPES, M. A.; RABELO, G. F.. Diagnóstico da automação na produção leiteira. Ciência Agrotécnica, Lavras, v.32, n.2, p.635-639, 2008.

BOUFLEUR, A. C.; GIACOMINI, C. S.; RIBEIRO, E.; RIBEIRO, F.; FERNANDES, D.; QUEIROZ, T. M. D.. Construção de um protótipo de um tanque para produção de chá com controle de temperatura e de nível. Revista de Engenharia e Tecnologia, v.6, n.3, p.197-207, 2014.

BRAGA, N. C.. Eletrônica básica para mecatrônica. São Paulo: Saber, 2005

CUAICAL, C. J. V.. Diseño de la automatización de un prototipo de línea de producción de quesos maduros. Ibarra: Universidad Técnica Del Norte, 2017.

FIGUEREDO, J. L. G. M.; SILVA, D. N.; DUENHAS, L. H.; BOTREL, T. A.. Construção e calibração de um manômetro de leituras digitais microprocessado. Irriga, v.11, p.492-499, 2006.

LIMA, L. P.; PEREZ, R.; CHAVES, J. B. P.. A indústria de laticínios no Brasil: um estudo exploratório. Boletim Centro de Pesquisa de Processamento de Alimentos-B. CEPPA, Curitiba, v.35, n.1, 2017.

MACEDO, D. A.; ZANIOLO, J. A.; ROMÃO, J. S.; SILVESTRIN, P. D.; QUEIROZ, T. M.. Desenvolvimento de protótipo para controle automático do processo de fermentação malolática na produção de vinho tinto. Revista de Engenharia e Tecnologia, v.8, n.2, p.64-69, 2016.

OLIVEIRA, A. M.; KURIHARA, R. Y.; SILVA, F. F.; SILVA, F. G.; RIBEIRO JUNIOR, J. C.; BELOTI, V.. Condições higiênicosanitárias da produção de queijos tipo mussarela e minas frescal comercializados no norte do Paraná. Revista do
Instituto de Laticínios Cândido Tostes, Juiz de Fora, v.72, n.1, p.40-47, 2017a.

OLIVEIRA, A. M. R.; CAVALCANTI, G. O.. Sistema Automatizado de Controle de Abastecimento de Água Proveniente de Poços Artesianos com Monitoramento Remoto. Revista de Engenharia e Pesquisa Aplicada, v.2, n.2, p.128-135, 2017b. DOI: http://dx.doi.org/10.25286/repa.v2i2.574

OLSON, N. F.. Automation in the cheese industry: a review. Journal of Dairy Science, v.53, n.8, p.1144-1150, 1970.

PIVARO, J.. Equipamentos com alta tecnologia possibilitam segurança e redução de custos na produção de leite, cremes, manteiga, queijos, bebidas lácteas e demais derivados de leite. Indústria de Laticínios, v.21, n.123, p.50-56, 2016.

REBELLO JUNIOR, C. J.. Sistema de aquisição de dados agrometeorológicos baseado no microcontrolador "Basic Step". Monografia (Bacharelado em Ciência da Computação) - Universidade Federal de Lavras, Lavras, 2004.

RIZZOLO, J. A.. Biofiltração de vapores de gasolina com diferentes concentrações de etanol: uma abordagem da realidade brasileira frente à grande demanda de carros flexfuel. Dissertação (Mestrado em Processos Biotecnológicos), Universidade Federal do Paraná, Curitiba, 2010.

SANGALETTI, N.; PORTO, E.; BRAZACA, S. G. C.; YAGASAKI, C. A.; DALLA DEA, R. C.; SILVA, M. V.. Estudo da vida útil de queijo Minas. Ciência e Tecnologia de Alimentos, Campinas, v.29, n.2, p.262-269, 2009.

SILVA, F. M.. Eletricidade. Santa Maria: Universidade Federal de Santa Maria, 2015.

SILVA, L. A.; LEMOS JUNIOR, A. C.. Protótipo de um sensor de temperatura wireless. In: CONFERÊNCIA DE ESTUDOS EM ENGENHARIA ELÉTRICA, 12. Anais. Uberlândia: Universidade Federal de Uberlândia, 2014.

SILVA, T. E.. Estudo do shelf life do queijo minas frescal artesanal e industrial. Dissertação (Mestrado em Zootecnia/Recursos Pesqueiros) - Instituto Federal de Educação, Ciência e Tecnologia Goiano, Rio Verde, 2015.

SOUTO NETO, G. L.; ROCHA, E. F.; SILVA, R. B.; LOPES 
JUNIOR, J. O.; VIEIRA, V. E. L.. Projeto de um sistema de controle para uma bancada de laboratório para ensino em controle de processos. Brazilian Journal of Development, v.5, n.11, p.23269-23281, 2019. DOI: http://doi.org/10.34117/bjdv5n11-047

SOUZA, I. A.; GIOVANNETTI, A. C. S.; SANTOS, L. G. F.; GANDRA, S. O. S.; MARTINS, M. L.; RAMOS, A. L. S.. Qualidade microbiológica de queijo minas frescal comercializado na Zona da Mata Mineira. Revista do Instituto de Laticínios Cândido Tostes, Juiz de Fora, v.72, n.3, p.152-162, 2017. DOI: http://doi.org/10.14295/2238$\underline{6416 . v 72 i 3.598}$

TEXAS INSTRUMENT. LM35 Precision Centigrade
Temperature Sensors. TEXAS INSTRUMENT, 2017.

VALERO, N. V.; SOLDÁ, C. E.; CARVALHO, P. F.; FOLADOR. T; QUEIROZ, T. M.. Protótipo de elevador de canecas com sistema de acionamento via controle remoto. Revista de Engenharia e Tecnologia, v.6, n.1, p.183-193, 2014.

VIEIRA, L. C.; LOURENÇO JUNIOR, J. B.. Tecnologia de Fabricação do Queijo Minas Frescal. Comunicado Técnico 125. Embrapa, 2004.

VILELA, L. A.; GERVÁSIO, E. S.; SOCCOL, O. J.; BOTREL, T. A.. Sistema para aquisição de dados de pressão e vazão usando microcomputador. Revista Brasileira de Agrocomputação, v.1, n.2, p.25-30, 2001.

A CBPC - Companhia Brasileira de Produção Científica (CNPJ: 11.221.422/0001-03) detém os direitos materiais desta publicação. Os direitos referem-se à publicação do trabalho em qualquer parte do mundo, incluindo os direitos às renovações, expansões e disseminações da contribuição, bem como outros direitos subsidiários. Todos os trabalhos publicados eletronicamente poderão posteriormente ser publicados em coletâneas impressas sob coordenação da Sustenere Publishing, da Companhia Brasileira de Produção Científica e seus parceiros autorizados. Os (as) autores (as) preservam os direitos autorais, mas não têm permissão para a publicação da contribuição em outro meio, impresso ou digital, em português ou em tradução. 